\title{
Visualizing Input-Output Data: Some New Techniques Applied to the Amazon Region'
}

\author{
Joaquim José Martins Guilhoto y Umberto Antonio Sesso Filho
}

\begin{abstract}
Since the initial input-output models conceived by Leontief in the 1930's, the input-output theory has gone through a lot of development at the theoretical as well as applied point of view. However, despite all the progress, there is still one point that needs further consideration into the analysis, i.e., how to visualize, and to analyze, in an easy way the vast amount of data and information contained into input-output systems. In this paper two different ways to look at input-output data are presented, i.e., landscapes and electroeconograms. The examples are conducted using as the main source of data an interregional input-output system consisted of 10 regions (nine Amazon states and the Rest of Brazil region) constructed for the year of 1999 by Guilhoto et al. (2002) for the Amazon Bank (BASA).
\end{abstract}

JEL Classification: R15, C67.

Key Words: Productive Structure, Input-Output, Amazon Region.

\section{Visualizando la Matriz de Insumo Producto: Algunas Nuevas Técnicas Aplicadas para la Región Amazónica}

RESUMEN: Desde los modelos de insumo producto concebidos por Leontief en la década de 1930, la teoría de insumo producto y su práctica han pasado por muchos cambios y avances. Sin embargo, a pesar de todo este adelanto hay un punto que necesita mejor análisis y atención, es decir, cómo visualizar y cómo analizar de una manera fácil, la gran cantidad de números y informaciones contenidas en un sistema de insumo producto. En este trabajo son presentados dos modos de interpretación para las informaciones encerradas en el sistema de insumo producto, o sea, topografía

\footnotetext{
The first author would like to thank FAPESP (Fundação de Amparo à Pesquisa do Estado de São Paulo) for the financial support that made possible to attend and to present a previous version of this paper at the $43^{\text {rd }}$ Congress of the European Regional Science Association in Jyväskylä, Finland.

Postal address: Joaquim J.M. Guilhoto, Departamento de Economia - FEA, Universidade de São Paulo, Av. Prof. Luciano Gualberto, 908, FEA II - Cidade Universitária, São Paulo, SP 05508-900, Brasil.

The authors also wish to acknowledge the valuable comments received from the referees, which certainly helped in improving the quality of the paper.
}

Recibido: 23 de marzo de 2004 / Aceptado: 26 de septiembre de 2005. 
económica y electroeconogramas. Los ejemplos realizados están basados en informaciones procedentes de un sistema interregional de insumo producto construido para 10 regiones (nueve Estados de Amazonia y el Resto de Brasil) por Guilhoto et al. (2002), para el Banco de Amazonia (BASA), para el año de 1999.

Clasificación JEL: R15, C67.

Palabras Clave: Amazonia; Estructura Productiva; Insumo-Producto.

\section{Introduction}

In assessing the economic impact of a sector or group of sectors on a single or multiregional economy, input-output analysis has proven to be a popular method. However, there has a problem in displaying all the information that can be obtained from this analytical approach. In this paper, we have tried to set new directions in the use of input-output analysis by presenting an improved way of looking at it, by using electroeconograms and landscapes. Essentially, it will now be possible to visualize, in a simple picture, all the relations in the economy as well as being able to view how one sector is related to the other sectors/regions in the economy. These relations can be measured in terms of structural changes, production, value added, employment, imports, etc. While all the possibilities cannot be explored in this paper, the basic idea is given here and the smart reader can uncover all the various possibilities.

To illustrate the power of analysis provided by the electroeconograms and the economic landscapes, an application is made to an interregional input-output system consisted of 10 regions (nine Amazon states and the Rest of Brazil region) constructed for the year of 1999 by Guilhoto et al. (2002) for the Amazon Bank (BASA).

In the next section it is presented the methodology used in the analysis, the third section will present a brief overview of the Amazon region. The results are presented in the fourth section and the final comments in the last section.

\section{Theoretical Background}

The intersectoral flows in a given economy can be represented by the following system:

$$
X=A X+Y
$$

where $X$ is a (nx1) vector with the value of the total production in each sector, $Y$ is a (nx1) vector with values for the final demand, and A is a (nxn) matrix with the technical coefficients of production (Leontief, 1951). In this model, the final demand vector can be treated as exogenous to the system, such that the level of total production can be determined by the final demand, i.e., 


$$
\begin{gathered}
X=B Y \\
B=(I-A)^{-1}
\end{gathered}
$$

where $B$ is a (nxn) matrix of the Leontief inverse.

\subsection{Multipliers}

From the multipliers results it is possible to measure the direct and indirect effects of a change in the final demand over production, income, employment, etc. (see Miller and Blair, 1985).

From the Leontief inverse matrix (B) defined above one has that the production multiplier of type I for each economic sector is given by:

$$
\begin{aligned}
& P_{j}=\sum_{i=1}^{n} b_{i j} \\
& j=1, \ldots, n
\end{aligned}
$$

where $P_{j}$ is the production multiplier for sector $j$ and $b_{i j}$ is an element of matrix $B$.

\subsection{The Rasmussen/Hirschman Approach}

The work of Rasmussen (1956) and Hirschman (1958) led to the development of indices of linkage that have now become part of the generally accepted procedures for identifying key sectors in the economy. Define $b_{i j}$ as a typical element of the Leontief inverse matrix, $B ; B^{*}$ as the average value of all elements of $B$, and if $B_{i}$. are the associated typical column and row sums, then the indices may be developed as follows:

Backward linkage index (power of dispersion):

$$
U_{j}=\left[B_{\bullet j} / n\right] / B^{*}
$$

Forward linkage index (sensitivity of dispersion):

$$
U_{i}=\left[B_{i \bullet} / n\right] / B^{*}
$$

One of the criticisms of the above indices is that they do not take into consideration the different levels of production in each sector of the economy, what it is done by the pure linkage approach presented in the next section.

\subsection{The Pure Linkage Approach}

As presented by Guilhoto, Sonis and Hewings (1996) the pure linkage approach can be used to measure the importance of the sectors in terms of production generation in the economy. 
144 Martins Guilhoto, J.J. and Sesso Filho, U.A.

Consider a two-region input-output system represented by the following block matrix, $A$, of direct inputs:

$$
A=\left(\begin{array}{c|c}
A_{j j} & A_{j r} \\
\hline A_{r j} & A_{r r}
\end{array}\right)
$$

where $A_{j j}$ and $A_{r r}$ are the quadrate matrices of direct inputs within the first and second region and $A_{j r}$ and $A_{r j}$ are the rectangular matrices showing the direct inputs purchased by the second region and vice versa.

From [7], one can generate the following expression:

$$
B=(I-A)^{-1}=\left(\begin{array}{ll}
B_{j j} & B_{j r} \\
B_{r j} & B_{r r}
\end{array}\right)=\left(\begin{array}{cc}
\Delta_{j j} & 0 \\
0 & \Delta_{r r}
\end{array}\right)\left(\begin{array}{cc}
\Delta_{j} & 0 \\
0 & \Delta_{r}
\end{array}\right)\left(\begin{array}{cc}
I & A_{j r} \Delta_{r} \\
A_{r j} \Delta_{j} & I
\end{array}\right)
$$

where:

$$
\begin{gathered}
\Delta_{j}=\left(I-A_{j j}\right)^{-1} \\
\Delta_{r}=\left(I-A_{r r}\right)^{-1} \\
\Delta_{j j}=\left(I-\Delta_{j} A_{j r} \Delta_{r} A_{r j}\right)^{-1} \\
\Delta_{r r}=\left(I-\Delta_{r} A_{r j} \Delta_{j} A_{j r}\right)^{-1}
\end{gathered}
$$

By utilizing this decomposition (equation 8), it is possible to reveal the process of production in an economy as well as derive a set of multipliers/linkages.

From the Leontief formulation:

$$
X=(I-A)^{-1} Y
$$

and using the information contained in equations [8] through [12], one can derive a set of indexes that can be used: a) to rank the regions in terms of its importance in the economy; b) to see how the production process occurs in the economy.

From equations [8] and [13] one obtains:

$$
\left(\begin{array}{l}
X_{j} \\
X_{r}
\end{array}\right)=\left(\begin{array}{cc}
\Delta_{j j} & 0 \\
0 & \Delta_{r r}
\end{array}\right)\left(\begin{array}{cc}
\Delta_{j} & 0 \\
0 & \Delta_{r}
\end{array}\right)\left(\begin{array}{cc}
I & A_{j r} \Delta_{r} \\
A_{r j} \Delta_{j} & I
\end{array}\right)\left(\begin{array}{l}
Y_{j} \\
Y_{r}
\end{array}\right)
$$

which leads to the definitions for the Pure Backward Linkage (PBL) and for the Pure Forward Linkage (PFL), i.e.,

$$
\begin{aligned}
& P B L=\Delta_{r} A_{r j} \Delta_{j} Y_{j} \\
& P F L=\Delta_{j} A_{r j} \Delta_{r} Y_{r}
\end{aligned}
$$

where the PBL will give the pure impact on the rest of the economy of the value of the total production in region $j$, $\left(\Delta_{j} Y_{J}\right)$ : i.e., the impact that is free from $a$ ) the demand inputs that region $j$ makes from region $j$, and $b$ ) the feedbacks from the rest of the 
economy to region $j$ and vice-versa. The PFL will give the pure impact on region $j$ of the total production in the rest of the economy $\left(\Delta_{r} Y_{r}\right)$.

As the PBL and PFL are show in current values, the pure total linkage (PTL) can be obtained by adding the two previous indices, i.e.,

$$
P T L=P B L+P F L
$$

The pure linkage indices can also be normalized by the average value of the sectors in the economy such that the normalized indices show how many times a sector is bigger or smaller than the average sector in the economy. In such a way it is possible to use these indices to a direct comparison of the productive structure of economies with different sizes and currencies. In the same way they do allow for a time comparison in economies with inflation or that have changed their currency.

\section{A brief overview of the amazon region}

The main indicators of the Amazon region are presented in Table 1. The Amazon region consists of nine (Acre, Amapá, Amazonas, Pará, Rondônia, Roraima, Tocantins, Maranhão, and Mato Grosso) out of the 27 Brazilian States (Brazil is a Federative Republic with 26 states and 1 Federal District ). In general, this region is characterized by having a great share of the Brazilian territory, however, with a small population, and a low density of population per $\mathrm{km}^{2}$. The Amazon region has a share of $6.5 \%$ of the Brazilian GDP, and the values for the per capita income are below the national average.

Following Guilhoto et al. (2002) the service sector is the most important one for the Amazon region, with a share of $61.2 \%$ of its GDP, against a share of $59.7 \%$ for Brazil as a whole. For the agricultural and industrial sectors the shares are respectively, $16.0 \%$ and $22.8 \%$ for the Amazon Region, and $8.0 \%$ and $32.3 \%$ for the Brazilian Economy.

Table 1. Main Indicators of the Amazon Region for 1999

\begin{tabular}{lccccc}
\hline \multicolumn{1}{c}{ Region } & $\begin{array}{c}\text { GDP } \\
(\text { US } \$ \text { Million })\end{array}$ & $\begin{array}{c}\text { Population } \\
(\text { Thousand })\end{array}$ & $\begin{array}{c}\text { Per Capita GDP } \\
(\text { US } \$)\end{array}$ & $\begin{array}{c}\text { Area } \\
\left(\text { Thousand } \mathrm{km}^{2}\right)\end{array}$ & $\begin{array}{c}\text { Density } \\
\left(\text { Pop }^{2} \mathrm{Km}^{2}\right)\end{array}$ \\
\hline Acre & 849 & 547 & 1,552 & 153 & 3.59 \\
Amapá & 864 & 462 & 1,869 & 143 & 3.24 \\
Amazonas & 8,485 & 2,761 & 3,073 & 1,571 & 1.76 \\
Pará & 9,090 & 6,098 & 1,491 & 1,248 & 4.89 \\
Rondônia & 2,740 & 1,360 & 2,015 & 238 & 5.72 \\
Roraima & 446 & 316 & 1,409 & 224 & 1.41 \\
Tocantins & 1,149 & 1,138 & 1,009 & 277 & 4.11 \\
Maranhão & 4,318 & 5,590 & 772 & 332 & 16.84 \\
Mato Grosso & 6,383 & 2,467 & 2,587 & 903 & 2.73 \\
Amazon Region & $\mathbf{3 4 , 3 2 3}$ & $\mathbf{2 0 , 7 4 0}$ & $\mathbf{1 , 6 5 5}$ & $\mathbf{5 , 0 8 8}$ & $\mathbf{4 . 0 8}$ \\
Rest of Brazil & 496,811 & 147,170 & 3,376 & 3,426 & 42.96 \\
Brazil & $\mathbf{5 3 1 , 1 3 4}$ & $\mathbf{1 6 7 , 9 1 0}$ & $\mathbf{3 , 1 6 3}$ & $\mathbf{8 , 5 1 4}$ & $\mathbf{1 9 . 7 2}$ \\
\hline
\end{tabular}

Source: IBGE (2002a), IBGE (2002b) 


\section{The productive structure of the amazon region}

Using the visual techniques of landscapes and electroeconograms, this section presents the main results obtained by applying the above methodology in the interregional inputoutput model constructed by Guilhoto et al. (2002) for 91 industries (sectors) and 141 commodities for 10 regions (Acre, Amapá, Amazonas, Pará, Rondônia, Roraima, Tocantins, Maranhão, Mato Grosso, and Rest of Brasil) for the year of 1999.

First it is presented and analysis of how the flow of goods and services take place among the region, then it is made a comparative study of the productive structure of the states of the Amazon region.

\subsection{Flow of Goods and Services}

Table 2 shows how the shares of total imports (intermediate and final consumption) made by one region are distributed among the source regions. It is possible to see the great dependence on the imports from the Rest of Brazil region, over 85\%, showing a small level of trade among the states of the Amazon region. This can be explained, in part, by the low level of industrialization found in the region as well as by transportation problems. The Rest of Brazil region buys products mainly from the states of Amazonas, Mato Grosso and Pará. The electronic goods produced in the Free Zone of Manaus can explain the great share of the Amazonas state, given that the industries producing in the Free Zone of Manaus can import the electronic components, used in production, free of duties.

The low flow and dependence among the Amazon region is confirmed by looking at Figures 1 to 3 that show the landscapes of the Leontief inverse for the interregional system, first considering the whole system (figure 1), them removing the columns and rows corresponding to the Rest of Brazil region (figure 2), and finally removing the values for the main diagonal matrices, which correspond to the intraregional flows (figure 3).

The states that have the most of the few links within the Amazon region are the ones of Amazonas and Mato Grosso, and to a less extent the states of Pará, Rondônia, and Maranhão.

Table 2. Share (\%) of Interregional Imports in the Total Imports of a Given Region

\begin{tabular}{lrrrrrrrrrr}
\hline \multicolumn{1}{c}{ Region } & \multicolumn{1}{c}{$A C$} & \multicolumn{1}{c}{$A P$} & \multicolumn{1}{c}{$A M$} & \multicolumn{1}{c}{$P A$} & \multicolumn{1}{c}{$R O$} & \multicolumn{1}{c}{$R R$} & $T O$ & $M A$ & $M T$ & $R B R$ \\
\hline Acre (AC) & & 0.07 & 0.07 & 0.03 & 0.20 & 0.06 & 0.04 & 0.05 & 0.05 & 0.74 \\
Amapá (AP) & 0.04 & & 0.04 & 0.08 & 0.02 & 0.05 & 0.04 & 0.05 & 0.01 & 0.65 \\
Amazonas (AM) & 4.30 & 3.05 & & 4.08 & 6.97 & 9.29 & 1.45 & 2.07 & 3.22 & 49.55 \\
Pará (PA) & 0.47 & 0.98 & 1.76 & & 0.43 & 0.55 & 2.02 & 3.78 & 0.34 & 13.04 \\
Rondônia (R0) & 3.61 & 0.24 & 3.20 & 0.13 & & 0.81 & 0.15 & 0.17 & 0.71 & 3.83 \\
Roraima (RR) & 0.02 & 0.02 & 0.08 & 0.01 & 0.01 & & 0.01 & 0.02 & 0.02 & 0.53 \\
Tocantins (TO) & 0.07 & 0.08 & 0.08 & 1.11 & 0.03 & 0.07 & & 1.39 & 0.06 & 2.09 \\
Maranhão (MA) & 0.46 & 0.48 & 0.42 & 2.15 & 0.15 & 0.40 & 4.29 & & 0.10 & 6.57 \\
Mato Grosso (MT) & 3.14 & 0.69 & 3.60 & 0.86 & 6.80 & 0.85 & 1.24 & 0.54 & & 22.99 \\
Rest of Brazil (RBR) & 87.89 & 94.38 & 90.75 & 91.54 & 85.39 & 87.92 & 90.75 & 91.95 & 95.49 & \\
Total & 100.00 & 100.00 & 100.00 & 100.00 & 100.00 & 100.00 & 100.00 & 100.00 & 100.00 & 100.00 \\
\hline
\end{tabular}

Source: Research Data. 
Figure 1. Landscape of the Leontief Inverse for the Interregional System

Row and Column Order: AC, AP, AM, PA, RO, RR, TO, MA, MT, RBR

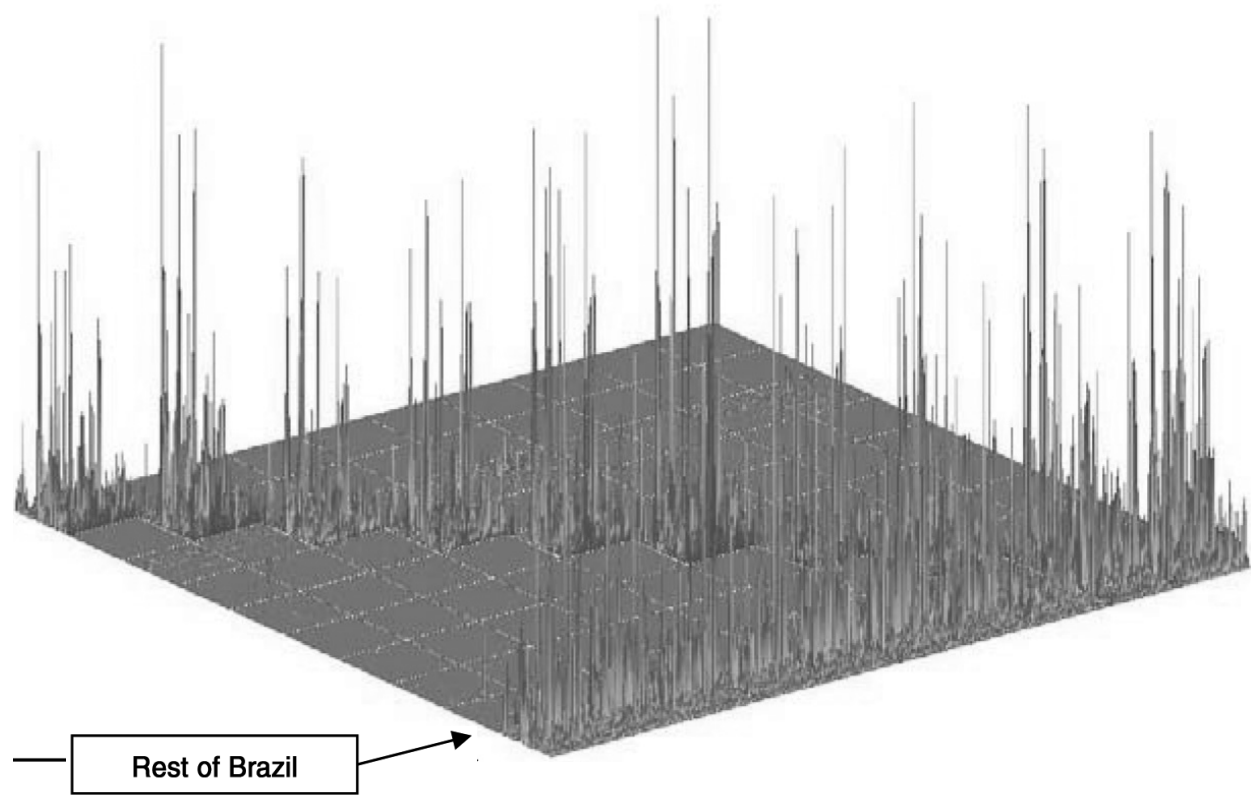

Figure 2. Landscape of the Leontief Inverse for the Interregional System, Without the Columns and Rows for the Rest of Brasil Region

Row and Column Order: AC, AP, AM, PA, RO, RR, TO, MA, MT, RBR

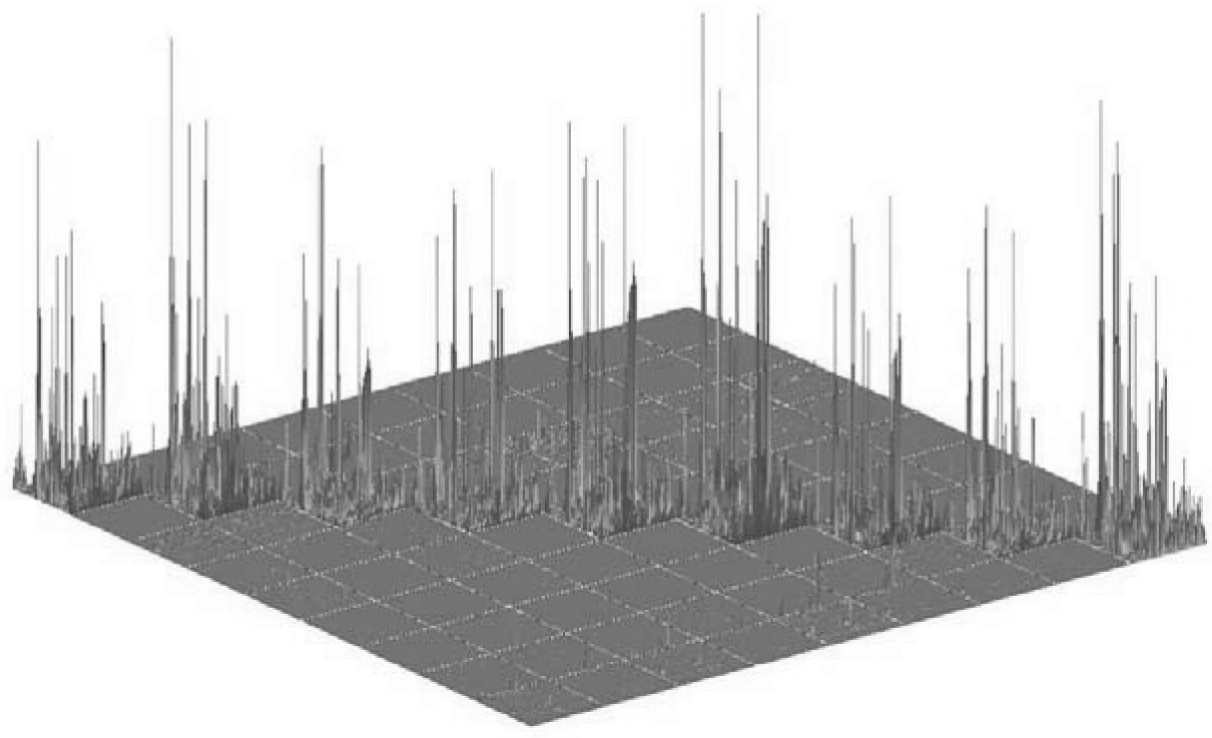


Figure 3. Landscape of the Leontief Inverse, Without: a) the Columns and Rows for the Rest of Brazil Region; and b) the Values for the Intraregional Flows

Row and Column Order: AC, AP, AM, PA, RO, RR, TO, MA, MT, RBR

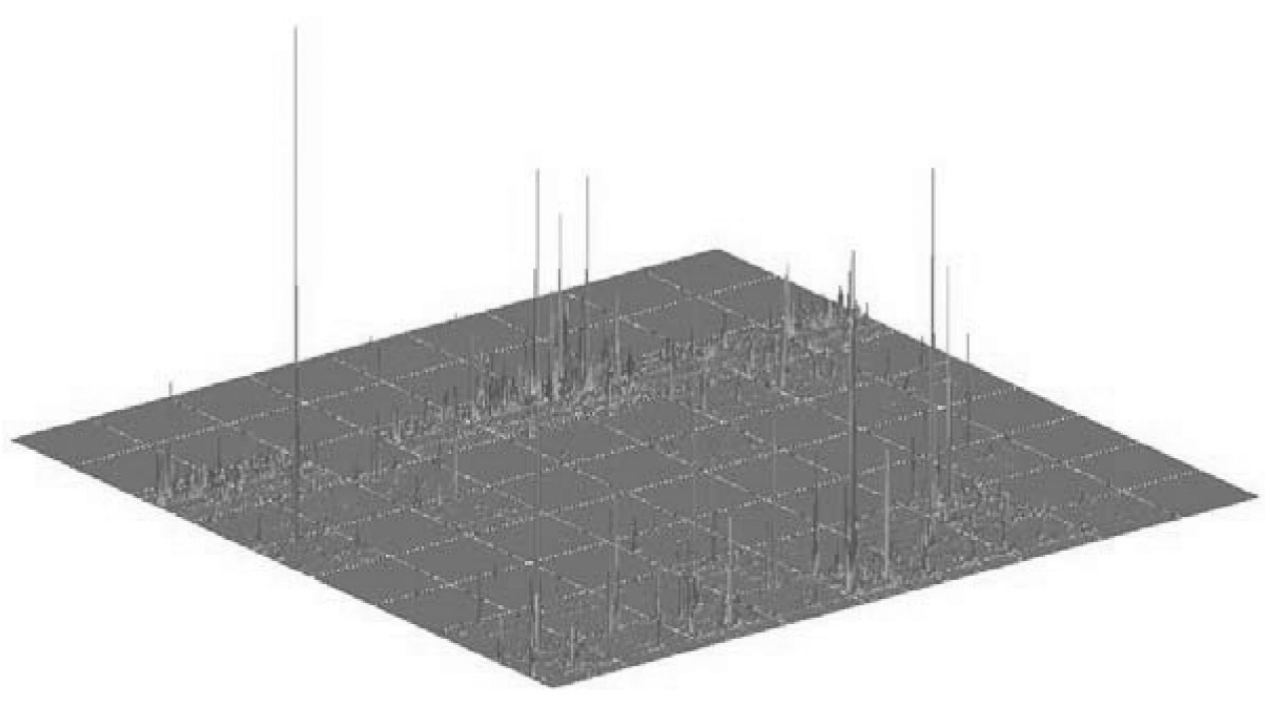

\subsection{Differences in the Productive Structure, The Electroeconograms}

Figures 4 to 9 show the Electroeconograms of the productive structure of the Amazon region. The concept of Electroeconogram is similar to the one for the electrocardiogram or the electroencephalogram in medicine that are used to measure the differences from a given standard. In that sense, using the Brazilian economy as a «numeraire» it is possible to examine how the results from a given region differ from the ones for the Brazilian economy. Then, one has that the higher the amplitude of the waves in the figures, the greater the difference in the productive structures.

In general one can observe that the Rest of Brazil region has values near zero, showing a greater similarity of this region with the country considered as a whole. This result was already expected given that the Rest o Brazil region has a share of around $93.5 \%$ of the Brazilian GDP.

The Amazon region shows states that differ in their productive structure, but it can also be observed similarities among the productive structure of the following states: Acre and Amapá; Amazonas and Pará; Rondônia, Roraima and Tocantins. The sates of Maranhão and Mato Grosso have, visually, productive structures relatively different from the other Amazon region states and between themselves. 
Figure 4. Electroeconogram of Production Multipliers, Type I, for the Amazon Region Interregional System

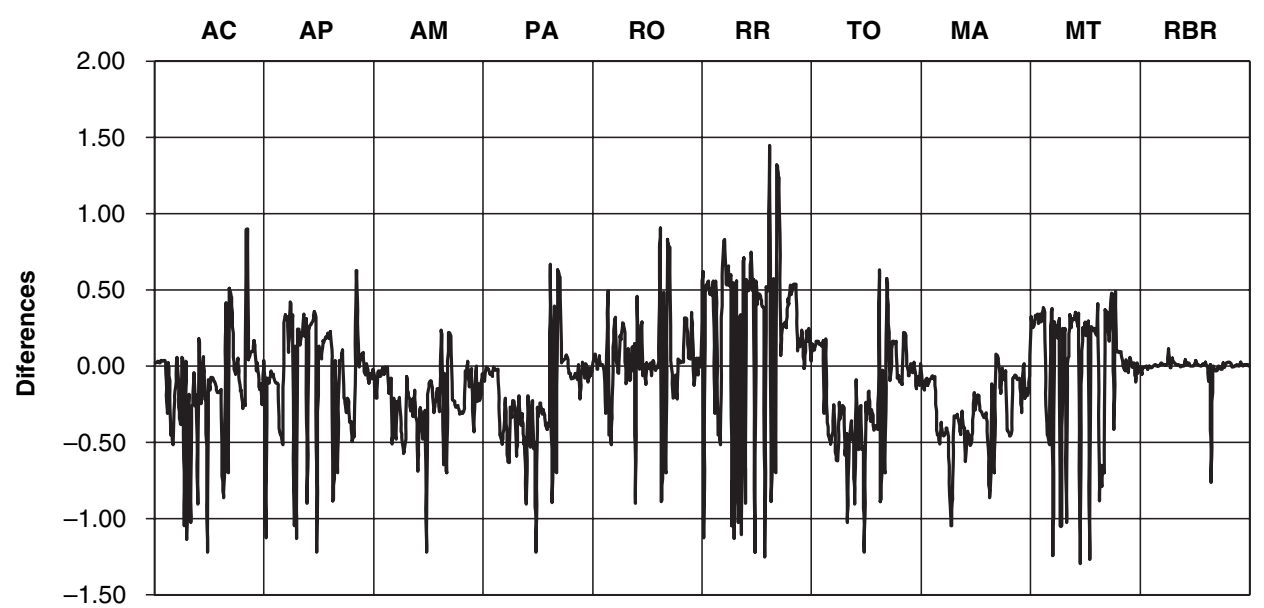

Source: Input-output matrix

States

Figure 5. Electroeconogram of the Hirschman-Rasmussen Backward Linkages for the Amazon Region Interregional System

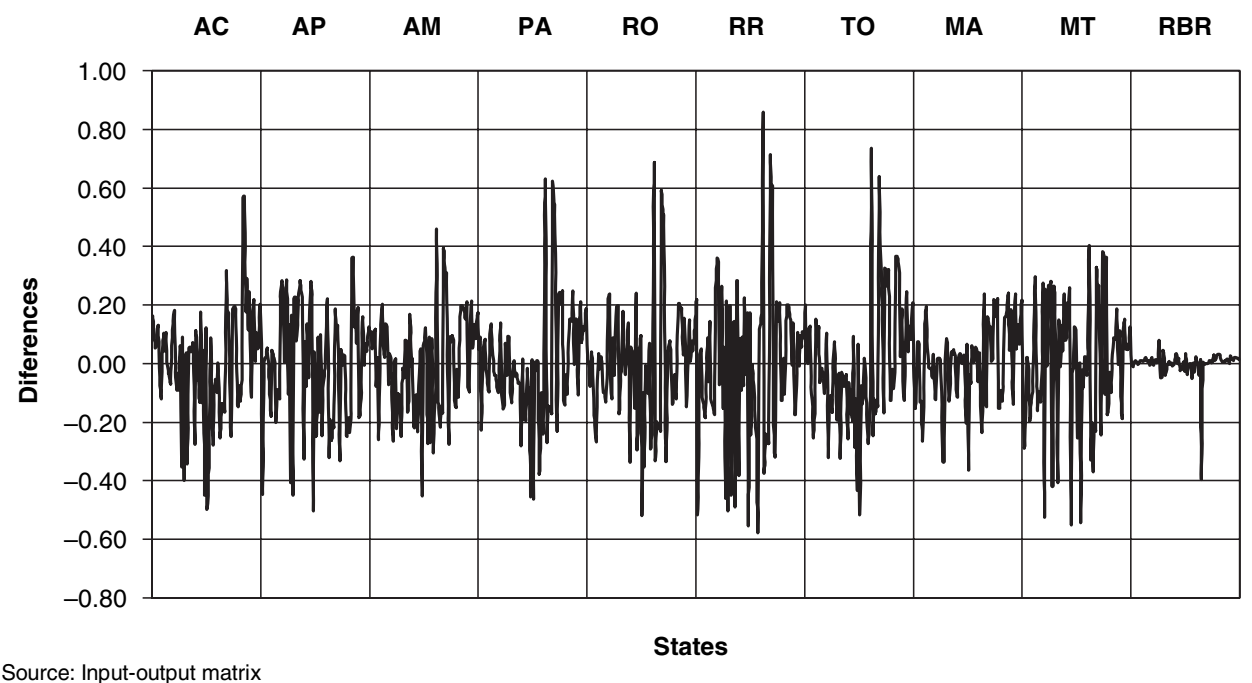


Figure 6. Electroeconogram of the Hirschman-Rasmussen Forward Linkages for the Amazon Region Interregional System

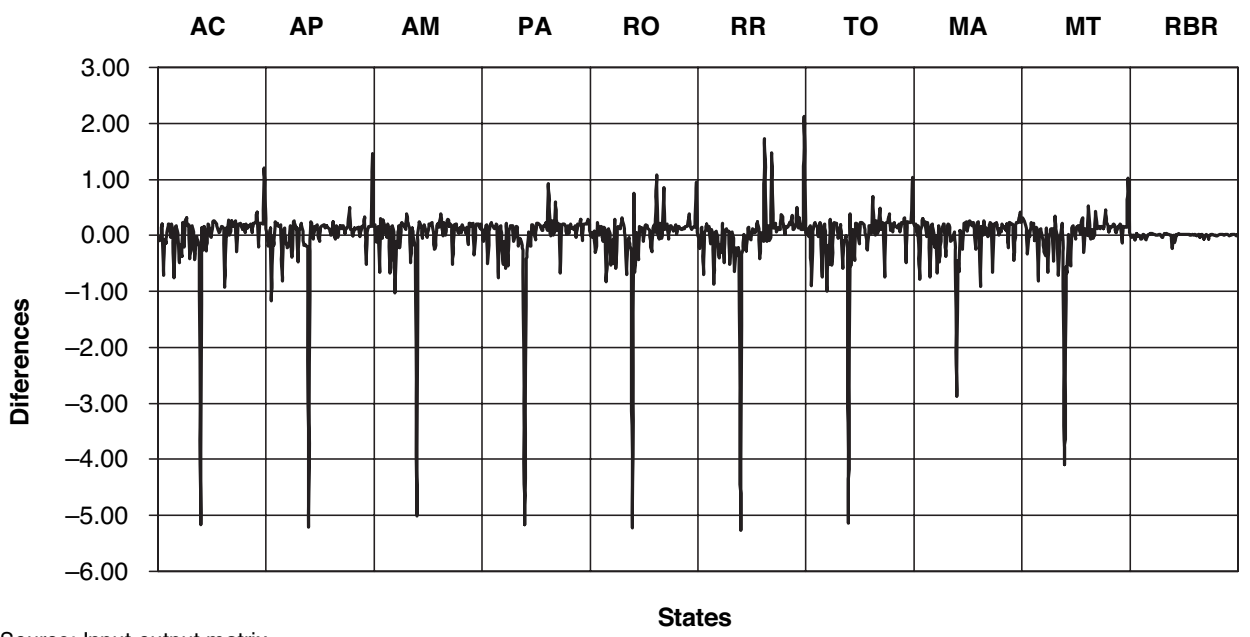

Figure 7. Electroeconogram of the Pure Normalized Backward Linkages for the Amazon Region Interregional System

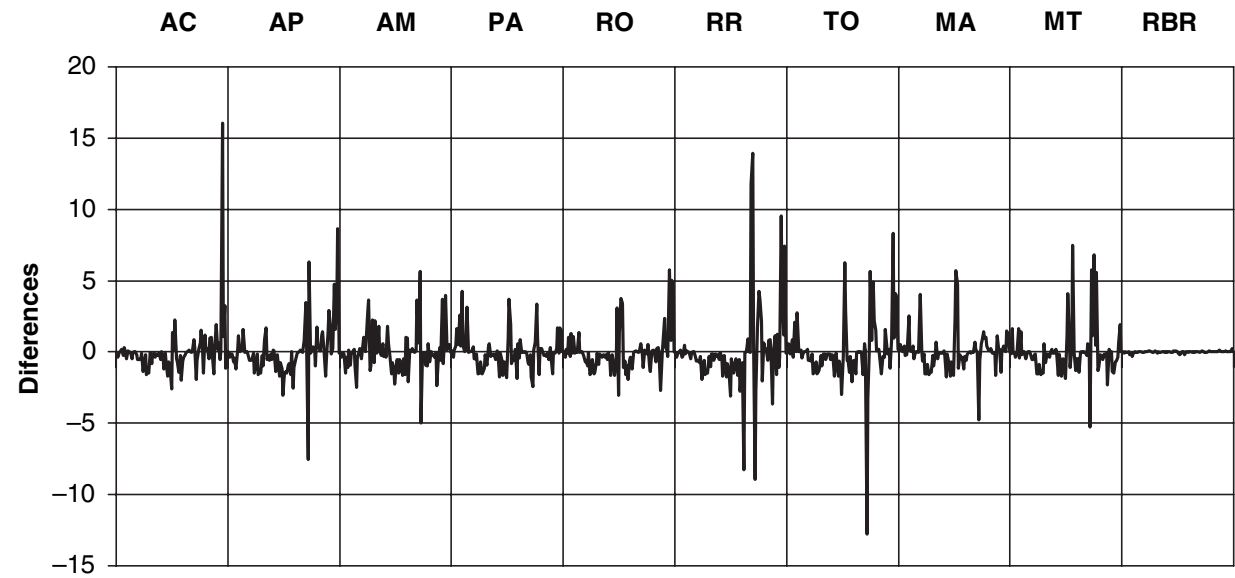


Figure 8. Electroeconogram of the Pure Normalized Forward Linkages for the Amazon Region Interregional System

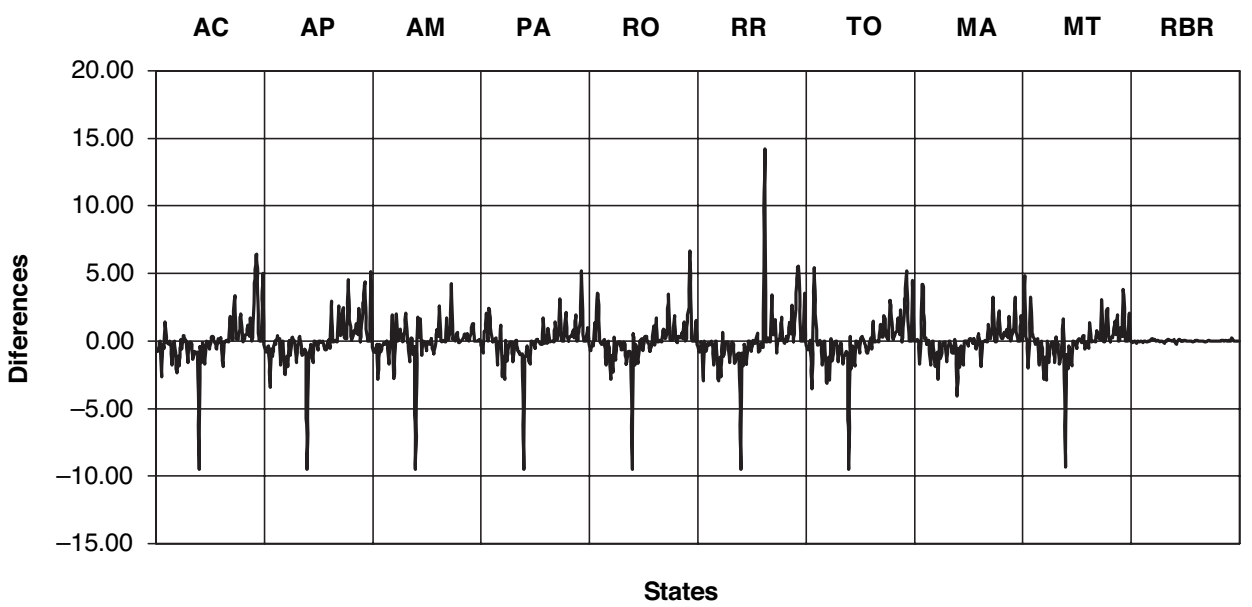

Source: Input-output matrix

Figure 9. Electroeconogram of the Pure Normalized Total Linkages for the Amazon Region Interregional System

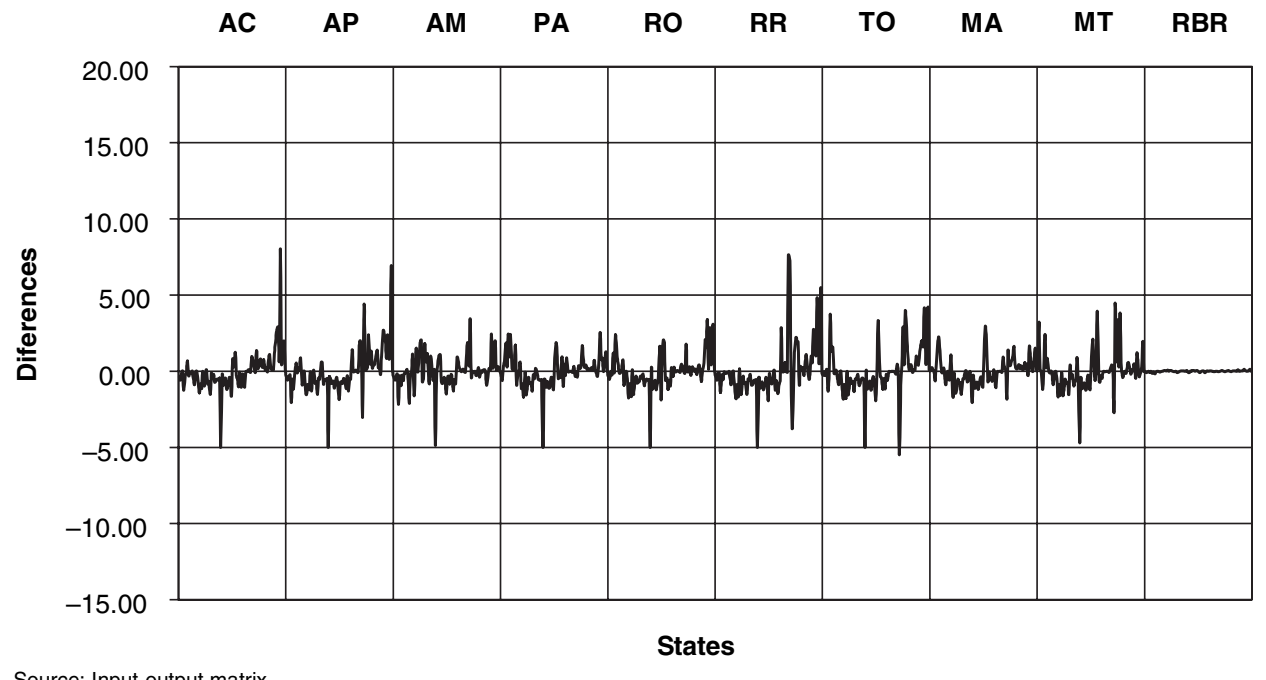




\section{Conclusions}

This paper presented new concepts of analysis through the use of electroeconograms and econmic landscapes. These concepts can be used to better understand, in a visual, way, how the structural changes take place in the economy as a whole, and how the transactions vary in magnitude and direction among the regions.

The use of electroeconomgrams and economic landscapes is illustrated in this paper through an application to the Brazilian Amazon region.

This study has show that the states of the Amazon region show a dependence on the Rest of Brazil region, given that the flow of goods and services between the region states and the REst of Brazil are more intense than the flow among the region states.

There is a relative heterogeneity in the productive structure of the states of the Amazon region, however, a closer look of the data con show that some economic activities can be important for the economic and social development of the region as a whole.

As a final remark, it must be stressed that the use of electroeconograms and economic landscapes in the analysis do not replace previous methods of analysis with input-output systems; it only uncovers a new and better way of showing information contained in an input-output table that otherwise would be difficult to analyze and to show to a broader audience of non input-output specialists.

\section{References}

Guilhoto, J.J.M. et al. (2002): «Projeto de Estimação de Matrizes de Insumo-Produto para a Região e os Estados da Amazônia Legal». Banco da Amazônia - BASA.

Guilhoto, J.J.M.; Sonis, M. y Hewings, G.J.D. (1996): «Linkages and Multipliers in a Multiregional Framework: Integrations of Alternative Approaches». Discussion Paper, 96-T-8 Regional Economics Applications Laboratory, University of Illinois, Urbana.

Hirschman, A.O. (1958): The Strategy of Economic Development. New Haven, Yale University Press.

IBGE (2002a): Contas Regionais do Brasil, 1985-2000. Rio de Janeiro.

IBGE (2002b): Brasil em Números 2002. Rio de Janeiro. Vol. 10.

Leontief, W. (1951): The Structure of the American Economy. Second Edition. New York: Oxford University Press.

Miller, R.E., and Blair, P.D. (1985): Input-Output Analysis: Foundations and Extensions. Englewood Cliffs: Prentice-Hall.

Rasmussen, P. (1956): Studies in Intersectoral Relations. Amsterdam, North Holland. 